\title{
Inventarisasi Jamur Makroskopis di Pulau Bawean Jawa Timur
}

\section{Macroscopic Mushroom Inventory in Bawean Island East Java}

\author{
Nugraheni T, Apipah TA \\ Biologi Pecinta Alam Sunan Kalijaga (BIOLASKA) Yogyakarta
}

Nugraheni, T., \& Apipah, T. A. (2020). Inventarisasi Jamur Makroskopis di Pulau Bawean Jawa Timur. Jurnal Mikologi Indonesia, 4(1), 143-148. doi: 10.46638/jmi.v4i1.83

\begin{abstract}
Abstrak
Pulau Bawean merupakan kawasan suaka alam yang berada di antara pulau Jawa dan Kalimantan. Keadaan topografi kawasan memungkinkan ditemukanya jenis-jenis jamur makroskopis. Penelitian ini bertujuan untuk mengetahui jenis jamur yang ditemukan di pulau Bawean dan mengetahui apakah jamur yang ditemukan memiliki potensi sebagai pangan maupun obat. Pengambilan data dilakukan menggunakan metode survei langsung di lapangan. Lokasi sampling meliputi kawasan suaka margasatwa (SM) yaitu pinggiran hutan dan daerah aliran sungai yang kawasannya cukup lembap, sampling juga dilakukan diluar kawasan SM yaitu di daerah mangrove. Berdasarkan penelitian yang telah dilakukan didapatkan hasil 20 jenis jamur. Jamur yang ditemukan berasal dari 2 filum, 5 ordo, 11 famili dan 14 genus. Jamur paling banyak ditemukan di kawasan pinggiran hutan dan daerah aliran sungai yaitu sebanyak 17 jenis. Sedangkan pada daerah mangrove hanya ditemukan 3 jenis jamur. Beberapa potensi yang dimiliki oleh jamur yang ditemukan yaitu sebagai bahan obat, pangan dan dapat meningkatkan laju fermentasi.
\end{abstract}

Kata kunci - Bawean - jamur alam - makroskopis - potensi

\begin{abstract}
Bawean island is a nature reserve area between Java and Kalimantan. The topography of the region allows the discovery of macroscopic fungi. This study aims to determine the type of fungus found on Bawean island and find out whether the fungus found has potential as food or medicine. Data is collected using the direct survey method in the field. Sampling locations include the wildlife reserve area, which is the edge of the forest and the watershed, which is quite humid, sampling is also done outside the wildlife reserve area, namely in the mangrove area. Based on research that has been done, the results obtained 20 types of mushrooms. The fungus found came from 2 phyla, five orders, 11 families, and 14 genera. The most common fungus is found in the periphery of the forest and watershed as many as 17 species. Whereas in the mangrove area only found three types of mushrooms. Some of the potential possessed by mushrooms found are as a medicinal ingredient, food and can increase the rate of fermentation.
\end{abstract}

Keywords - Bawean - macroscopic - potency - wild mushroom 


\section{Pendahuluan}

Indonesia merupakan salah satu negara yang dilewati oleh garis khatulistiwa sehingga Indonesia beriklim tropis. Iklim tersebut menyebabkan Indonesia memiliki keanekaragaman hayati yang tinggi. Jamur atau fungi merupakan salah satu organisme yang sering ditemui di lingkungan sekitar kita terutama saat musim penghujan karena saat musim penghujan kondisi lingkungan menjadi lebih lembap yang memungkinkan jamur dapat tumbuh (Wahyudi et al., 2016).

Jamur atau fungi merupakan organisme yang bersifat heterotrof. Jamur dapat ditemukan tumbuh pada pohon tumbang, kayu lapuk, serasah organik, atau pada organisme yang masih hidup. Berdasar ukuran tubuhnya, jamur dapat dibagi menjadi dua kelompok besar yaitu jamur mikroskopis yaitu kelompok jamur yang berukuran $\leq 1 \mathrm{~mm}$ dan jamur makroskopis yaitu jamur yang berukuran $\geq 1 \mathrm{~mm}$ (Keizer, 2007). Jamur makroskopis memiliki tubuh buah yang dapat dilihat dengan mata telanjang atau tanpa bantuan mikroskop. Jamur makroskopis ini beberapa berasal dari kelompok Ascomycetes dan sebagian besar dari kelompok Basidiomycetes (Budiarsi, 2017). Dari sisi ekologi, sebagian jamur memiliki peran sebagai dekomposer (saprofit) bersama dengan bakteri dan beberapa spesies protozoa, sehingga banyak membantu proses dekomposisi bahan organik untuk mempercepat siklus materi. Dengan demikian jamur memiliki peran dalam menyuburkan tanah dengan cara menyediakan nutrisi bagi tumbuhan (Wahyudi et al., 2016). Selain sisi ekologi, jamur juga dapat dimanfaatkan sebagai bahan pangan maupun obat.

Pulau Bawean merupakan kawasan suaka alam yang berada di antara pulau Jawa dan Kalimantan (Trimanto, 2014). Keadaan topografi kawasan Suaka Margasatwa (SM) dan Cagar Alam (CA) pulau Bawean adalah berbukit-bukit, bergunung-gunung dan bergelombang. Diluar kawasan terdapat banyak persawahan warga, mangrove, tambak dan juga sungai. Berdasarkan keadaan topografi tersebut, memungkinkan ditemukanya jenis-jenis jamur makroskopis, baik jamur yang berasal dari kelompok Basidiomycota maupun Ascomycota. Berdasarkan latar belakang tersebut, penelitian ini bertujuan untuk mengetahui jenis jamur yang ditemukan di pulau Bawean dan potensinya sebagai bahan pangan maupun obat.

\section{Metode Penelitian}

\section{Batasan lokasi sampling di lapangan}

Lokasi sampling yaitu di kawasan SM pulau Bawean khususnya pinggiran hutan dan daerah aliran sungai yang kawasannya cukup lembap, selain itu sampling juga dilakukan diluar kawasan SM yaitu di daerah mangrove.

\section{Waktu dan tempat}

Penelitian ini dilakukan pada bulan Januari 2019 di kawasan SM pulau Bawean dan wilayah sekitar kawasan SM.

\section{Pengambilan data}

Pengambilan data dilakukan menggunakan metode survei langsung di lapangan (Purwanto et al., 2014), dengan menjelajahi pinggiran hutan, daerah aliran sungai dan daerah mangrove. Jamur makroskopis yang ditemukan akan diamati meliputi warna, tekstur dan habitatnya. Kemudian dilakukan pengambilan gambar keseluruhan (satu tubuh, tudung bagian atas dan bawah).

\section{Identifikasi jamur makroskopis}

Identifikasi jamur dilakukan dengan mengacu pada beberapa monograf fungi dan jurnal-jurnal penelitian terbaru. Potensi jamur makroskopis diketahui berdasarkan kajian 
literatur. Beberapa monograf yang digunakan antara lain $A$ Guide to common fungi of the Hunter-Central Rivers region (Moore \& O' Sullivan, 2014), Queensland Fungal Record (Leonard, 2017) dan Fungi In Australia (Hubregtse, 2018).

\section{Hasil}

Berdasarkan penelitian yang telah dilakukan di kawasan SM Pulau Bawean dan kawasan mangrove di luar kawasan SM, didapatkan hasil 20 jenis jamur sesuai tabel 1 dan tabel 2. Jamur yang ditemukan berasal dari 2 filum, 5 ordo, 11 famili dan 14 genus. Jamur paling banyak ditemukan di kawasan pinggiran hutan dan daerah aliran sungai yaitu sebanyak 17 jenis. Sedangkan pada daerah mangrove hanya ditemukan 3 jenis jamur.

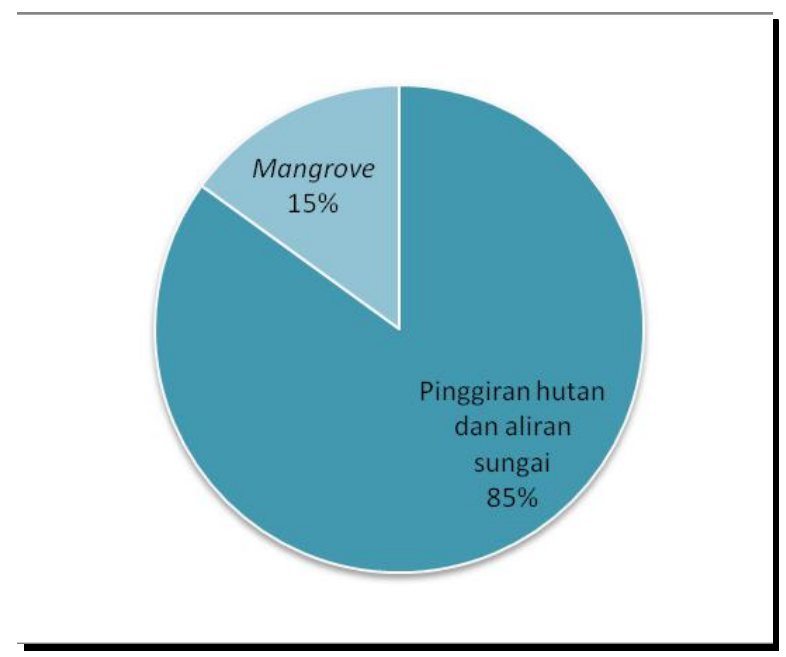

Gambar 1. Diagram perbandingan jumlah jenis jamur makro di wilayah pinggiran hutan, daerah aliran sungai dan mangrove.

Tabel 1. Daftar jamur yang ditemui di wilayah pinggiran hutan dan daerah aliran sungai

\begin{tabular}{|c|c|c|c|c|}
\hline Filum & Ordo & Famili & Genus & Spesies \\
\hline \multirow[t]{12}{*}{ Basidiomycota } & Agaricales & Nidulariaceae & Cyathus & Cyathus sp. \\
\hline & & Psathyrellaceae & Coprinellus & Coprinellus sp. \\
\hline & & Hygroporaceae & Hygrocybe & Hygrocybe sp. \\
\hline & & Marasmiaceae & Marasmius & Marasmius sp. 1 \\
\hline & & & & Marasmius sp. 2 \\
\hline & Polyporales & Meruliaceae & Cymathoderma & Cymathoderma sp. \\
\hline & & Ganodermataceae & Ganoderma & Ganoderma sp. 1 \\
\hline & & & & Ganoderma sp. 2 \\
\hline & & Fomitopsidaceae & Laetiporus & Laetiporus sp. \\
\hline & & Polyporaceae & Microporus & Microporus sp. \\
\hline & & & Polyporus & Polyporus sp. 1 \\
\hline & & & Lentinus & Lentinus sp. \\
\hline
\end{tabular}




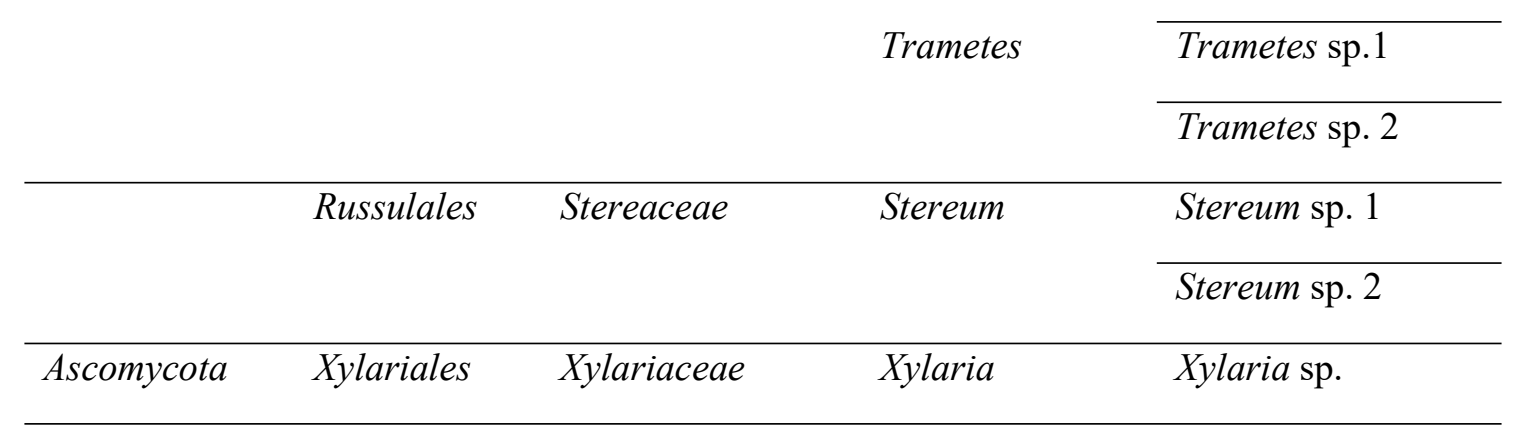

Tabel 2. Daftar jamur yang ditemui di wilayah mangrove

\begin{tabular}{ccccc}
\hline \multirow{2}{*}{ Filum } & Ordo & Famili & Genus & Spesies \\
\hline Basidiomycota & Dacrymycetales & Dacrymycetaceae & Dacryopinax & Dacryopinax sp. \\
\cline { 2 - 5 } & Polyporales & Ganodermataceae & Ganoderma & Ganoderma sp. 3 \\
\cline { 3 - 5 } & & Polyporaceae & Polyporus & Polyporus sp. 2 \\
& & & & \\
& & &
\end{tabular}

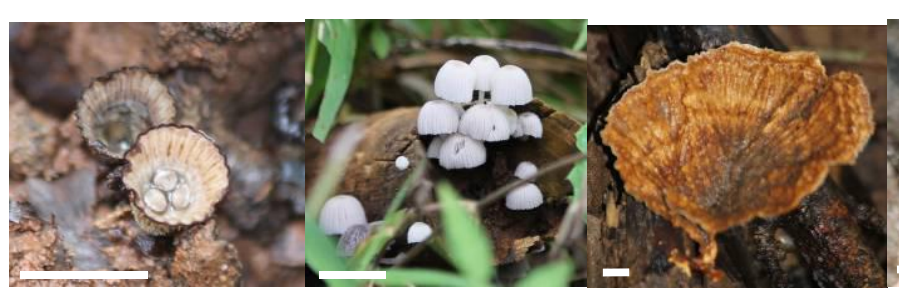

(1)

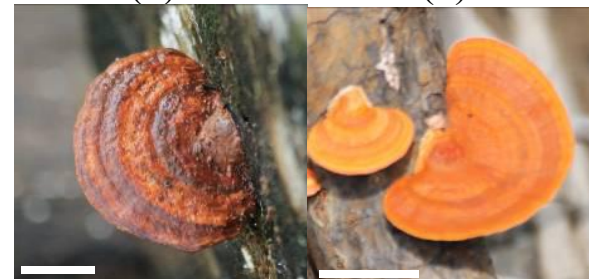

(6)
(3)

(7)

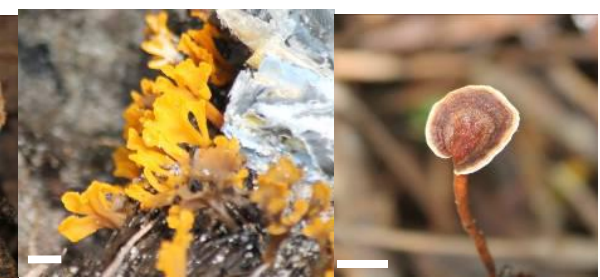

(4)
(5)
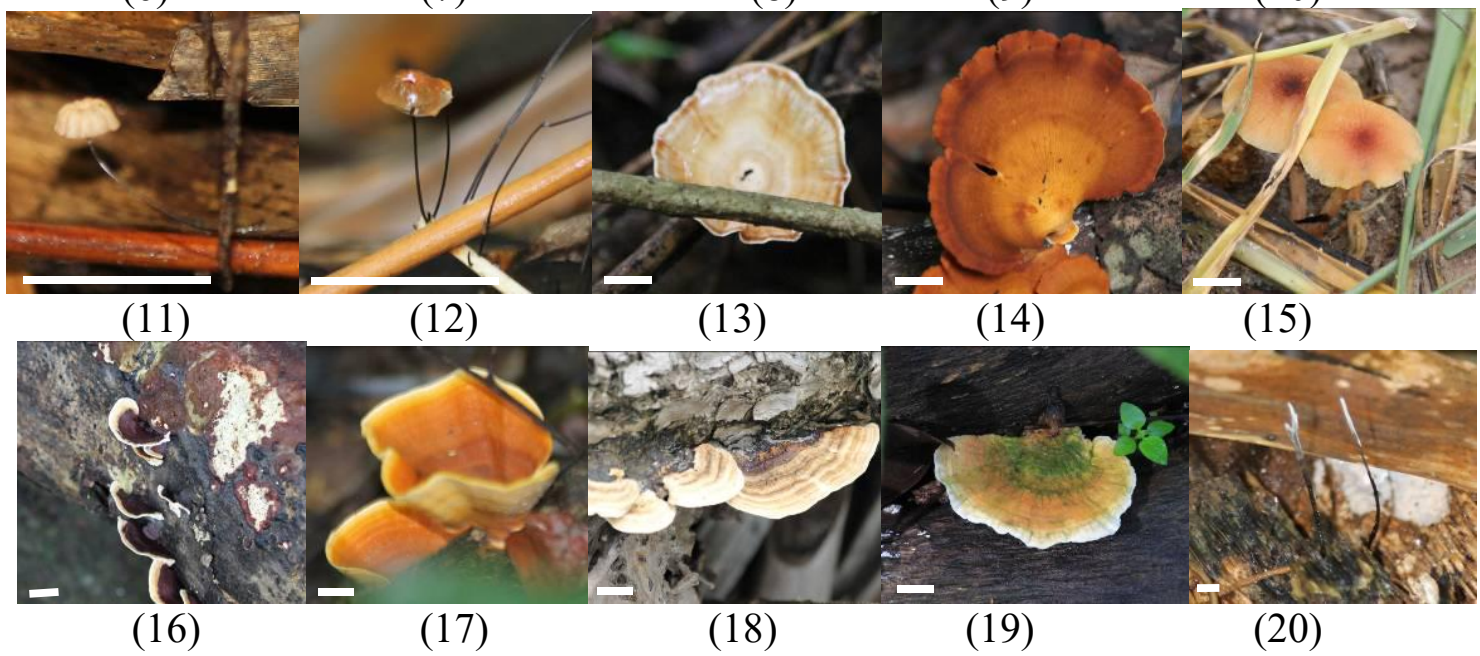

ambar 2. Spesimen jamur makroskopis yang ditemukan di pinggiran hutan, daerah aliran sungai dan mangrove. (1) Cyathus sp., (2) Coprinellus sp., (3) Cymathoderma sp., (4) Dacryopinax sp., (5) Ganoderma sp. 1, (6) Ganoderma sp. 2, (7) Ganoderma sp. 3, (8) Hygrocybe sp., (9) Laetiporus sp., (10) Lentinus sp., (11) Marasmius sp. 1, (12) Marasmius sp. 2, (13) Microporus sp., (14) Polyporus sp. 1, (15) Polyporus sp. 2, 
(16) Stereum sp. 1, (17) Stereum sp. 2, (18) Trametes sp.1, (19) Trametes sp. 2, (20) Xylaria $\mathrm{sp}$. Standar skala : $1 \mathrm{~cm} / 10 \mathrm{~mm}$.

\section{Pembahasan}

Berdasarkan penelitian yang telah dilakukan, jumlah jenis jamur yang ditemukan pada pinggiran hutan dan sungai memiliki presentase $85 \%$ yang jumlah tersebut lebih banyak dari pada kawasan mangrove yaitu sebesar $15 \%$ sesuai dengan Gambar 2. Hal tersebut dikarenakan pada kawasan pinggiran hutan dan sungai ditemukan banyak pohon tumbang, serasah daun dan juga memiliki kanopi yang lebih tertutup serta kondisi lingkungan lebih lembap dari kawasan mangrove. Sedangkan pada kawasan mangrove kondisi cenderung lebih panas, tidak terdapat serasah daun dan sedikit pohon tumbang. Hal tersebut sesuai dengan Wahyudi et al., (2016) menyatakan bahwa jamur lebih mudah ditemui pada kondisi lingkungan yang lembab dan didukung dengan pernyataan Wulandari et al., (2016) bahwa fakta keadaan lapangan akan berpengaruh terhadap kelestarian organisme dan sumber daya hidup yang ada. Menurut Asnah (2010) dalam Khayati \& Warsito, (2016) jamur makroskopis dapat tumbuh di banyak habitat dari artik hingga tropis dan beberapa jamur makroskopis menunjukkan habitat yang spesifik.

Ordo yang paling banyak diperoleh dalam penelitian ini berasal dari ordo polyporales yaitu sebanyak 9 jenis di kawasan pinggiran hutan dan daerah aliran sungai, sedangkan pada kawasan mangrove ditemukan 2 jenis. Ordo polyporales memiliki ciri-ciri poroid hymenium, basidiokarpnya bervariasi mulai dari bentuk resupinate hingga bertangkai (Sastrahidayat 2011). Hal tersebut sesuai dengan Alexopoulus \& Mims (1979) dalam Hiola (2011), bahwa jenis jamur yang tergolong ordo Polyporales merupakan jenis jamur yang paling banyak ditemukan tumbuh pada batang pohon, baik jamur yang masih hidup maupun yang telah kering atau lapuk, dan sebagian jenis lainnya dapat beradaptasi dengan perubahan lingkungan. Ordo terbanyak selanjutnya yang ditemui dalam penelitian ini adalah ordo agaricales. Ordo ini memiliki ciri-ciri yang paling mudah dikenali yaitu berbentuk seperti payung. Menurut Nasution et al., (2018) menyatakan bahwa anggota ordo agaricales sangat banyak dan kompleks. Bahkan dalam beberapa penelitian jamur ini sering ditemui memiliki jumlah anggota terbanyak dalam penelitian tersebut. Hal tersebut didukung oleh Hubregtse (2018) bahwa dari 21 ordo pada subfilum Agaricomycotina, agaricales merupakan ordo terbesar yaitu mencapai 63\% dari spesies yang ada pada subfilum Agaricomycotina.

Beberapa jamur makroskopis yang ditemukan perlu dilakukan penelitian lebih lanjut dikarenakan memiliki potensi sebagai bahan pangan maupun obat. Jamur Ganoderma sp., di Cina, jamur ini selama berabad-abad sudah digunakan sebagai obat tradisional karena terbukti memiliki senyawa-senyawa bioaktif (Gandjar et al., 2006). Jamur lain yang memiliki potensi sebagai obat adalah jamur Trametes sp. yaitu sebagai anti mikroba dan Xylaria sp. karena dapat digunakan sebagai antibakteri (Fauzi et al., 2018). Selain sebagai obat, terdapat pula jamur yang dapat dikonsumsi seperti jamur Lentinus sp. (Noverita et al., 2017). Lentinus sp. dapat dikonsumsi ketika masih muda (Mortimer et al., 2014). Jamur Chyathus sp. pada spesies tertentu dapat dimanfaatkan untuk meningkatkan laju fermentasi, metabolisme nitrogen dan serat pada ternak (Putra et al., 2018), dapat juga digunakan untuk biodegradasi lignin (Putra et al., 2018). Jamur Marasmius sp. mampu mendegradasi selulosa menjadi lebih sederhana karna dapat menghasilkan enzim selulase (Putra et al., 2018).

\section{Ucapan Terima Kasih}

Terimakasih kepada Kelompok Studi BIOLASKA (Biologi Pecinta Alam Sunan Kalijaga) Yogyakarta yang telah menyelenggarakan Ekspedisi Baladewa di Pulau Bawean. Terimakasih kepada tim capung Ekspedisi Baladewa yang telah membantu dalam pengambilan data. 


\section{Pustaka}

Budiarsi. (2017). Inventarisasi Fungi Makroskopis di Kawasan Hutan Gunung Giribangun Kelurahan Girilayu Kecamatan Matesih Kabupaten Karanganyar. (Skripsi) Program Studi Pendidikan Biologi Fakultas Keguruan dan Ilmu Pendidikan Universitas Muhammadiyah Surakarta.

Fauzi, R., Hidayat, M. Y., \& Saragih, G. S. (2018). Jenis-jenis Jamur Makroskopis di Taman Nasional Kelimutu NTT. Jurnal WASIAN. 5(2), 67-78.

Gandjar, I., Sjamsuridzal, W., \& Oetari, A. (2006). Mikologi Dasar dan Terapan. Yayasan Obor Indonesia.

Hiola, S.T \& Fatmah. (2011). Keanekaragaman Jamur Basidiomycota Di kawasan Gunung Bawakaraeng (Studi Kasus: Kawasan Sekitar Desa Lembanna Kecamatan Tinggi Moncong Kabupaten Gowa). Bionature. 12(2), 93-100.

Hubregtse, J. (2018). Fungi in Australia Basidiomycota. Field Naturalists Club.

Keizer, G. J. (2007). The Complete Encyclopedia of Mushrooms. Rebo International.

Khayati, L., \& Warsito, H. (2016). Keanekaragaman Jamur Kelas Basidiomycetes di Kawasan Lindung KPHP Sorong Selatan. Prosiding Symbion Prodi Pbio FKIP UAD.

Leonard, P. (2017). Queensland Fungal Record. Queensland Mycological Society.

Moore, S., \& O' Sullivan, P. (2014). A guide to common fungi of the Hunter-Central Rivers region. Ligare Pty Ltd.

Mortimer, P. E., Xu, J., Karunarathna, S. C., \& Hyde, K. D. (2014). Mushrooms for Trees and People: A Field Guide to Useful Mushrooms of the Mekong Region. World Agroforestry Centre.

Nasution, F., Prasetyaningsih, S. R., \& Ikhwan, M. (2018). Identifikasi Jenis dan Habitat Jamur Makroskopis di Hutan Larangan Adat Rumbio Kabupaten kampar Provinsi Riau. Wahana Forestra: Jurnal Kehutanan, 13(1), 64-76.

Noverita, Sinaga, E., \& Setia, T. M. (2016). Jamur Makro Berpotensi Pangan dan Obat di Kawasan Cagar Alam Lembah Anai dan Cagar Alam Batang Palupuh Sumatra. Jurnal Mikologi Indonesia, 1(1):,15-27.

Purwanto, P.B., Zaman, M.N., Yusuf, M., Romli, M., Syafi'i, I., \& Hardhaka, T. (2017). Inventarisasi Jamur Makroskopis di Cagar Alam Nusakambangan Timur Kabupaten Cilacap Jawa Tengah. Proceeding Biology Education Conference, 14(1), 79-82.

Putra, I. P., Rahmadi, S., \& Nadiah, C. (2018).Ragam dan Potensi Jamur Makro asal Taman Wisata Mekarsari Jawa Barat. Al-Kauniyah: Journal of Biology, 11(2), 133-150.

Sastrahidayat \& Rochdjatun, I. (2011). Mikologi (Ilmu Jamur). Universitas Brawijaya Press.

Trimanto. (2014). Analisis Vegetasi dan Estimasi Biomassa Stok Karbon Pohon pada Tujuh Hutan Gunung, Suaka Alam Pulau Bawean. Berita Biologi,13(3), 321-332.

Wahyudi, Roh, T., Rahayu, S., \& Azwin. (2016). Keanekaragaman Jamur Basidiomycota Di Hutan Tropis Dataran Rendah Sumatera, Indonesia. Wahana Forestra: jurnal kehutanan, 11(2), 21-33.

Wulandari, E. Y., Faturrahman, \& Sukiman. (2016). Jenis-jenis Makrofungi Polyporaceae di TWA Suranadi Kecamatan Narmada Kabupaten Lombok Barat. Bio Wallacea Jurnal Ilmiah Ilmu Biologi, 2(2), 132-136. 